\title{
Dynamic Modeling of the Main Blow in Basic Oxygen Steelmaking Using Measured Step Responses
}

\begin{abstract}
CAROLIEN KATTENBELT and B. ROFFEL
In the control and optimization of basic oxygen steelmaking, it is important to have an understanding of the influence of control variables on the process. However, important process variables such as the composition of the steel and slag cannot be measured continuously. The decarburization rate and the accumulation rate of oxygen, which can be derived from the generally measured waste gas flow and composition, are an indication of changes in steel and slag composition. The influence of the control variables on the decarburization rate and the accumulation rate of oxygen can best be determined in the main blow period. In this article, the measured step responses of the decarburization rate and the accumulation rate of oxygen to step changes in the oxygen blowing rate, lance height, and the addition rate of iron ore during the main blow are presented. These measured step responses are subsequently used to develop a dynamic model for the main blow. The model consists of an iron oxide and a carbon balance and an additional equation describing the influence of the lance height and the oxygen blowing rate on the decarburization rate. With this simple dynamic model, the measured step responses can be explained satisfactorily.
\end{abstract}

DOI: $10.1007 / \mathrm{s} 11663-008-9184-0$

(C) The Author(s) 2008. This article is published with open access at Springerlink.com

\section{INTRODUCTION}

TO improve control of basic oxygen steelmaking and to enable dynamic optimization, the process should be modeled dynamically. To develop a dynamic model, the influence of changes in control variables, such as the lance height, the oxygen blowing rate, and the addition rates, on the process should be known. How the behavior of the process changes with time under the influence of changes in control variables can be investigated using an experimental approach. ${ }^{[1,2]}$ In this approach, the value of control variables is deliberately changed. One possibility is to change the control variables by making a step change and monitoring the process variable response.

In the literature, little information is published on step responses in basic oxygen steelmaking. ${ }^{[-6]}$ It is however known that an increase in oxygen input, either due to an increase in oxygen blowing rate r $^{[3-5]}$ or due to the addition of ore ${ }^{[6]}$ increases the decarburization rate. Furthermore, Anderson et al. ${ }^{[6]}$ published the delay between the occurrence of a change in a control variable such as the iron ore addition rate and a change in decarburization rate.

In this article, the step response to changes in control variables is determined experimentally in the first section. Using the measured step responses, a simplified

C. KATTENBELT, Researcher, is with the Research Group Control Systems Engineering, Hogeschool Arnhem-Nijmegen, Karveel 67, 7429 BK Colmschate, The Netherlands. Contact e-mail: c.kattenbelt@alum nus.utwente.nl B. ROFFEL, Professor, is with the Hogeschool ArnhemNijmegen, University of Twente, The Netherlands

Manuscript submitted March 6, 2008.

Article published online October 10, 2008. process model is developed in Section II. In that section, the measured and simulated step responses are compared. Finally, the conclusions are summarized.

\section{EXPERIMENTAL}

Due to the high temperatures and dusty environment involved in basic oxygen steelmaking, important process variables such as the steel composition and steel temperature can not be measured continuously. Therefore, in most steel plants, indirect measurements, such as waste gas flow, temperature, and composition, are used to monitor the process. The decarburization rate and the accumulation rate of oxygen inside the converter, which are commonly derived from waste gas measurements, can be used as an indication of the change in composition of the steel and the slag, respectively. ${ }^{[7,8]}$ The decarburization rate $\frac{d C}{d t}$ can be given by

$$
\frac{d C}{d t}=\frac{\phi_{w g}\left(\mathrm{CO}_{w g}+\mathrm{CO}_{2, w g}\right)}{V_{M}}
$$

where $\phi_{w g}$ is the measured waste gas flow, $\mathrm{CO}_{w g}$ and $\mathrm{CO}_{2, w g}$ are the measured percentage of carbon monoxide and carbon dioxide in the waste gasses, and $V_{M}$ is the molar volume. The measured accumulation rate of oxygen inside the converter $\frac{d \mathrm{O}}{d t}$ can be given by

$$
\frac{d \mathrm{O}}{d t}=\frac{d \mathrm{O}_{\text {lance }}}{d t}+\frac{d \mathrm{O}_{\text {additions }}}{d t}-\left(\frac{d \mathrm{O}_{w g}}{d t}-\frac{d \mathrm{O}_{\text {air }}}{d t}\right)
$$

where $\frac{d \mathrm{O}_{\text {lance }}}{d t}$ is the measured rate at which oxygen is blown into the converter, $\frac{d \mathrm{O}_{\text {additions }}}{d t}$ is the measured rate in which oxygen in additions enters the converter, $\frac{d \mathrm{O}_{w g}}{d t}$ is the measured rate at which oxygen leaves the converter 
through the waste gasses, and $\frac{d \mathrm{O}_{\text {air }}}{d t}$ is the measured rate at which air enters the waste gas system.

It is important that a measured step response accurately describes the influence of the change in a control variable. This is easiest during a period in the batch in which the decarburization rate and accumulation rate of oxygen remain constant, when no changes in control variables occur. Boom and Deo ${ }^{[3]}$ describe this period as the main blow period.

The step changes in lance height, oxygen blowing rate, and iron ore addition rate occurring during normal operation in a data set of 1006 batches were determined. For the measured response in the decarburization rate and the accumulation rate of oxygen to be attributed to a certain step change, no other step change in control parameters should occur before or after the specific step change. The time during which no other changes in control parameters occur is defined as the time for which that step change is well defined. The number of observations found of a particular type of step change depends on the time for which that type of step change is well defined. For example, if this time is 50 seconds, then the number of observed step changes in the oxygen blowing rate is 11 . If the time is increased to 60 seconds, then the number of observations reduces to only 5 .

For each type of step change, the time for which this step change is well defined is selected in such a way that the number of observations exceeds ten. Details of the step changes, such as the time for which that step change is well defined as well as the number of observations and the average step size, are shown in Table I.

To minimize the influence of disturbances on the step response, the step responses of all the observations of each type of step change were averaged. Normalization of the step response to zero starting conditions will make this possible. The average normalized step responses of the step change in oxygen blowing rate, lance height, and the addition rate of iron ore on the decarburization rate and accumulation rate of oxygen are shown in Figure 1. A decrease in oxygen blowing rate is not shown in this figure, because not enough welldefined steps of this type of step change were present in the available data set.

\section{PROCESS MODEL}

The measured step responses can be simulated using a process model. In basic oxygen steelmaking, reactions can take place at a number of sites including the slag

Table I. Steps Found in Dataset

\begin{tabular}{lccl}
\hline Independent Step & $\begin{array}{c}\text { Duration } \\
\text { Step }\end{array}$ & Observations & $\begin{array}{c}\text { Average Size } \\
\text { of Step }\end{array}$ \\
\hline $\mathrm{O}_{2}$ rate increase & $50 \mathrm{~s}$ & 11 & $2500\left(\mathrm{~nm}^{3} / \mathrm{h}\right)$ \\
Lance up & $90 \mathrm{~s}$ & 43 & $7(\mathrm{~cm})$ \\
Lance down & $60 \mathrm{~s}$ & 14 & $7(\mathrm{~cm})$ \\
Ore start & $120 \mathrm{~s}$ & 247 & $8(\mathrm{~kg} / \mathrm{s})$ \\
Ore stop & $90 \mathrm{~s}$ & 48 & $8(\mathrm{~kg} / \mathrm{s})$ \\
\hline
\end{tabular}
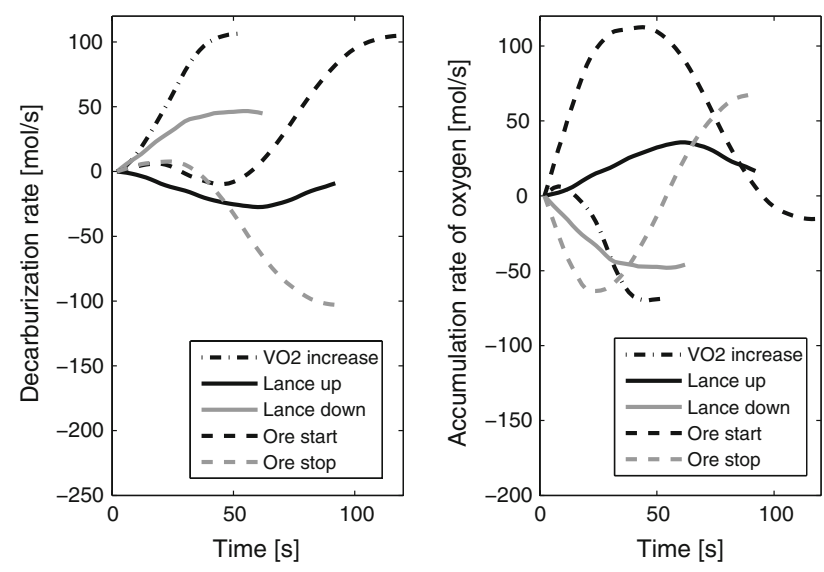

Fig. 1-Influence of step changes on decarburization rate and accumulation rate of oxygen (experimental).

foam where reactions take place between the iron droplets and the oxidizing slag and the hot spot directly under the oxygen jet. ${ }^{[3]}$

Meyer et al. ${ }^{[9]}$ have analyzed ejections of slag and metal emulsions from the tap hole. They have shown that a substantial portion of the liquid metal is emulsified into the slag during the batch. The authors concluded that at the height of refining most decarburization occurs within the slag-metal emulsion. It is therefore assumed that the majority of reaction takes place at the interface between the iron droplets and the slag.

Decarburization at the iron droplets in the slag occurs through a reaction with iron oxide:

$$
\begin{gathered}
\mathrm{Fe}+1 / 2 \mathrm{O}_{2} \rightarrow \mathrm{FeO} \\
\mathrm{C}+\mathrm{FeO} \rightarrow \mathrm{CO}+\mathrm{Fe}
\end{gathered}
$$

In the main blow period, mainly carbon and iron are oxidized. Silicium and titanium have already been oxidized before this period. If it is assumed that the oxidation of manganese, phosphorous, and sulfur is negligible during the main blow, the accumulation rate of oxygen in the converter can be calculated using an iron oxide balance:

$$
\begin{aligned}
\frac{d \mathrm{O}}{d t}= & \frac{d \mathrm{FeO}}{d t}=\frac{d \mathrm{FeO}_{\text {lance }}}{d t}+\frac{d \mathrm{FeO}_{\text {addition }}}{d t} \\
& -\left(1+p \mathrm{CO}_{2}\right) \frac{d C_{\text {reaction }}}{d t}
\end{aligned}
$$

where $\frac{d \mathrm{FeO}}{d t}$ is the change of iron oxide content in the slag, $\frac{d \mathrm{FeO}_{\text {lance }}}{d t}$ is the change in iron oxide due to the oxygen blown by the lance, $\frac{d \mathrm{FeO}_{\text {addition }}}{d t}$ is the change in iron oxide due to the additions, $p \mathrm{CO}_{2}$ is the percentage of carbon dioxide formed, and $\frac{d C_{\text {reaction }}}{d t}$ is the rate of decarburization.

Ghosh $^{[10]}$ has performed experiments in which oxygen was blown into a small induction furnace filled with carbon containing iron. He observed a complete consumption of the supplied oxygen and a continuous 
breaking and reforming of the oxide film. Because no oxygen was detected in the waste gas, it is assumed that all oxygen supplied by the lance is instantly converted to iron oxide:

$$
\frac{d \mathrm{FeO}_{\text {lance }}}{d t}=2 \mathrm{VO}_{2}
$$

where $V \mathrm{O}_{2}$ is the measured amount of oxygen blown through the lance. The amount of carbon in the steel bath changes due to decarburization and due to the dissolving of scrap. The model will be used to simulate the measured step responses, which last at most $120 \mathrm{sec}-$ onds. It is assumed that the influence of the dissolving of scrap on the change in carbon content in the steel can be neglected for such a short period. It is also assumed that the change in steel volume is negligible.

$$
\frac{d C}{d t}=-\frac{d C_{\text {reaction }}}{d t}=-V_{\text {steel }} \frac{d[\mathrm{C}]}{d t}
$$

where $V_{\text {steel }}$ is the volume of steel in the converter and $[\mathrm{C}]$ is the carbon concentration in the bath.

Several researchers performed experiments in which a small carbon containing iron droplet was dropped into a slag. ${ }^{[11-13]}$ They observed that the decarburization rate increased with increasing temperature, carbon concentration, and iron oxide concentration. It is therefore assumed that the decarburization reaction is rate limited and first order in carbon and iron oxide:

$$
\frac{d C_{\text {reaction }}}{d t}=V_{\text {steel }} A e^{\frac{-E a}{\mathrm{R} T}}[\mathrm{C}][\mathrm{FeO}]
$$

where $A$ is the frequency factor, $E a$ is the activation energy, $\mathrm{R}$ is the gas constant, $T$ is the bath temperature, $[\mathrm{FeO}]$ is the iron oxide concentration in the slag, and [C] is the carbon concentration in the steel.

Because the density of the steel and the slag is difficult to determine, the reaction rate is calculated using the molar carbon and iron oxide concentration. Because it is assumed that the steel volume is constant, it is incorporated in the constant $k_{0}$ :

$$
\frac{d C_{\text {reaction }}}{d t}=k_{0} e^{\frac{-E a}{\mathrm{R} T}}\left[\mathrm{C}^{*}\right]\left[\mathrm{FeO}^{*}\right]
$$

where $k_{0}$ is a reaction rate constant, $\left[\mathrm{FeO}^{*}\right]$ is the molar iron oxide concentration in the slag, and $\left[\mathrm{C}^{*}\right]$ is the molar carbon concentration in the steel.

The mass and size of iron droplets formed, as well as the residence time of the droplets in the slag, affect the reaction surface between the iron droplets and the slag at which part of the decarburization reaction takes place. In many excellent studies, detailed models have been developed to describe the droplet generation rate, droplet size distribution, and the residence time of the iron droplets in the slag. ${ }^{[14-19]}$

He and Standish ${ }^{[14]}$ have shown that the droplet generation rate is proportional to the oxygen flow rate and that the maximum droplet production is obtained at a critical lance height. Above this critical lance height, the droplet generation rate decreases with increasing lance height.
Deo and Boom ${ }^{[3]}$ and van der Knoop et al. ${ }^{[15]}$ have shown that the size distribution of the iron droplets generated by jet impact can be described using the Rosin-Rammler-Sperling distribution. The oxygen blowing rate and the lance height both influence the size distribution of the droplets.

Recent studies ${ }^{[17,18]}$ have shown that the residence time of the iron droplets in the slag highly depends on the size of the droplets. Subagyo et al. ${ }^{[19]}$ point out that, because the residence time of the iron droplets depends on the size of the droplets, the droplets' size distribution in the slag is different from the size distribution of the droplets generated by the oxygen jet.

The decarburization rate is influenced by the reaction surface between the iron droplets and the slag. In the previously mentioned studies, it has been shown that the droplet generation rate and the size distribution of the generated droplets can adequately be modeled and depend on the lance height and oxygen blowing rate. However, the reaction surface between the iron droplets and the slag depends on the droplet size distribution in the slag and the number of iron droplets in the slag. Both not only depend on the droplet generation rate and the size distribution of the generated droplets, but they also highly depend on the residence time of each the iron droplets. Moreover, while the iron droplets are in the slag, they react and the concentration of carbon in the iron droplets diminishes. The carbon concentration in the iron droplets is therefore not necessarily equal to the carbon concentration in the steel bath.

Thus, many effects play a role in how the lance height and oxygen blowing rate affect the decarburization rate. As a first approach, these effects are modeled using a simple empirical relationship:

$$
k_{0}=a+b V \mathrm{O}_{2}-c H_{\text {lance }}
$$

where $a, b$, and $c$ are model constants, $V \mathrm{O}_{2}$ is the oxygen blowing rate, and $H_{\text {lance }}$ is the lance height. Equation [10] is only valid for a limited range of lance heights and oxygen blowing rates, which are typical during main blow.

In contrast to what the calculation of the accumulation rate of oxygen in Eq. [2] suggests, the added iron ore cannot react immediately. Instead, the temperature of the iron ore needs to increase before it can dissolve. This heatup period is modeled as a time lag. Because this time lag is not incorporated in the calculation of the measured accumulation rate of oxygen (Eq. [2]), it is also not shown in the measured step response of the accumulation rate of oxygen to a step change in the iron ore addition rate in Figure 1. This explains why the measured step response in the decarburization rate hardly changes in the first 60 seconds, while the measured step response in the accumulation rate of oxygen in the converter changes significantly during this period.

Because the iron ore is added as lumps, the dissolution rate of iron ore is not uniform. The blown oxygen first has to react to iron oxide before it can react with carbon. When the oxygen blowing rate changes, it will take some time before the iron oxide content of the bath changes accordingly. Similarly, when the lance height 
and oxygen blowing rate are changed, it will take some time before the mass of droplets in the slag is changed accordingly. Therefore, an averaged iron ore addition rate, oxygen blowing rate, and lance height are used as inputs to Eqs. [5] and [10]. Averaging is a way to model a dynamic effect.

\section{COMPARISON MEASUREMENTS AND MODEL}

The measured step responses can be simulated using the model presented in Section III. The initial values of variables in the model and the size of steps are similar to those typical during the main blow. The activation energy and initial iron oxide concentration were selected in such a way that, at stationary input conditions, the decarburization rate and accumulation rate of oxygen remain more or less constant. The constants $a, b$, and $c$ and the delay and the size of averaging windows were adjusted to fit the model to measurement results.

The measured and modeled step responses to an increase in oxygen blowing rate, an increase and a decrease in lance height, and the start and stop of an ore addition are shown in Figures 2 through 4. In these figures, the step changes occurred at $t=10$ seconds. In Figure 2, it can be seen that the modeled and measured step responses to an increase in oxygen blowing rate correspond well. At 10 seconds the oxygen blowing rate is increased. At this moment, the increased oxygen input causes an increase of the iron oxide content in the slag (Eq. [5]). This can be seen as the initial small and brief increase in the accumulation rate of oxygen. The increase in oxygen blowing rate also increases the amount of iron droplets formed (Eq. [10]), thereby increasing the decarburization rate (Eq. [9]). The increase in decarburization rate decreases the iron oxide content in the slag (Eq. [5]). The increase in decarburization rate and the decrease in iron oxide content can both be seen in Figure 2 between 10 and 70 seconds. At around 70 seconds, the mass of iron droplets in the slag
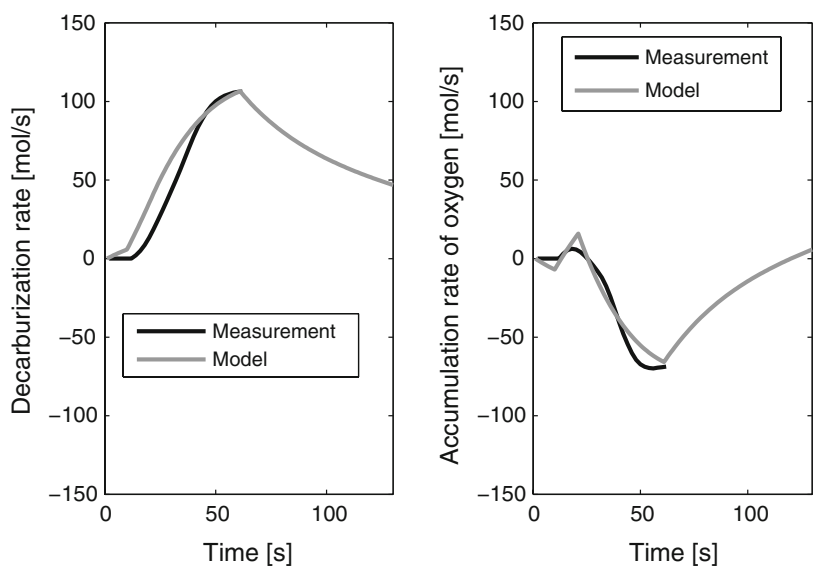

Fig. 2-Modeled and measured influence of an increase in the oxygen blowing rate on decarburization rate and accumulation rate of oxygen. no longer increases and has reached a stable level. At this point, the decreased iron oxide concentration in the slag reduces the decarburization rate (Eq. [9] until a decarburization rate is reached (at around 130 seconds)) at which oxygen consumption again matches the oxygen supply. In Figure 3, it can be seen that the modeled and measured step responses to an increase and a decrease in lance height correspond well.

At 10 seconds, the lance height is increased. The increase in lance height causes a decrease in the mass of iron droplets formed (Eq. [10]), which in turn decreases the decarburization rate (Eq. [9]) and consequently increases the iron oxide content of the bath (Eq. [5]). The decrease in the decarburization rate and the increase in the accumulation rate of oxygen can both be seen in Figure 3 between 10 and 70 seconds. At around 70 seconds, the mass of iron droplets in the slag no longer diminishes. At this point, the increased iron oxide concentration in the slag increases the decarburization rate (Eq. [9]) until oxygen consumption matches the oxygen supply. The step response to a decrease in lance height can be explained in a similar manner. In Figure 4, it can be seen that the modeled and measured step responses to the start or stop of an iron ore addition correspond reasonably well.

At 10 seconds, an ore addition is started. Initially, the temperature of the iron ore increases and there is no effect of the ore addition on the decarburization rate, as can been seen in Figure 4. (There is an effect on the accumulation rate of oxygen during this period. This is because the delay caused by the heating period is not considered in calculating the measured accumulation rate of oxygen in Eq. [2].) Then, at around 60 seconds, the ore starts to dissolve and it increases the iron oxide content in the slag (Eq. [5]). The increased iron oxide content causes an increase in the decarburization rate (Eq. [9]), which can be seen in Figure 4. The step response to the stop of ore addition can be explained in a similar manner. The difference between the model and experiment for the stop of an iron ore addition is larger. Other dynamic effects may play a role and could explain part of this difference.
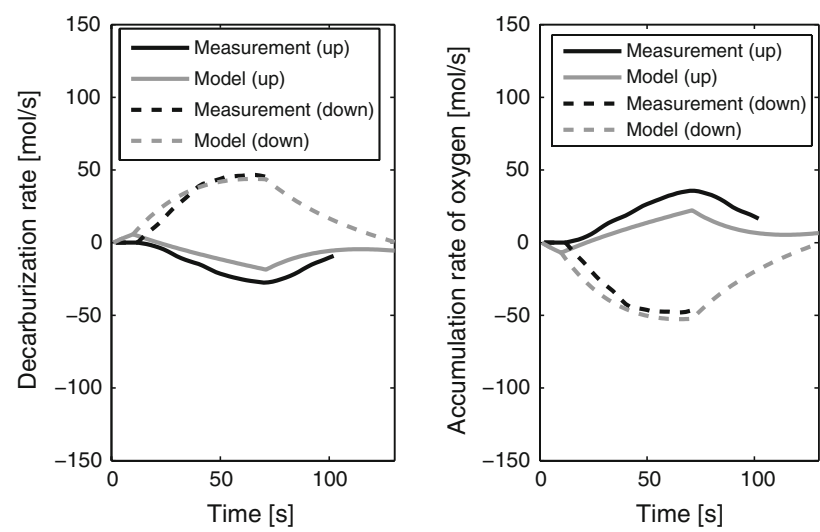

Fig. 3-Modeled and measured influence of an increase and a decrease in the lance height on the decarburization rate and the accumulation rate of oxygen. 

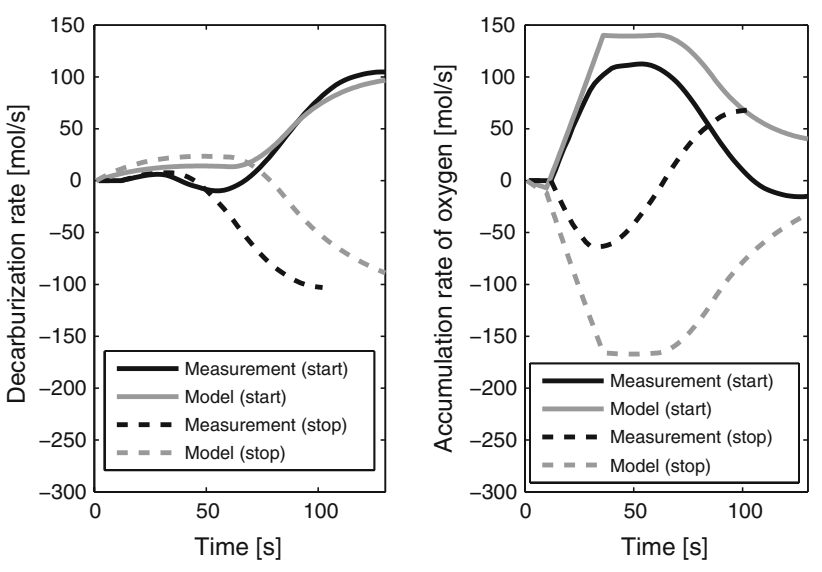

Fig. 4-Modeled and measured influence of an increase and a decrease in iron ore addition rate on decarburization rate and accumulation rate of oxygen.

\section{CONCLUSIONS}

The average normalized step responses to step changes in lance height, oxygen blowing rate, and addition rate of iron ore during main blow were determined in a data set containing 1006 batches. These step responses were satisfactorily simulated using a process model consisting of an iron oxide and a carbon balance and an additional equation describing the influence of the lance height and oxygen blowing rate on the amount of iron droplets in the slag and thereby on the decarburization rate.

It was found that an increase in the oxygen blowing rate and the iron ore addition rate causes an increase in the decarburization rate. Both step changes increase the oxygen supply to the converter. This increased oxygen supply is eventually matched by an equal increase in oxygen consumption and thus in an increase in the decarburization rate.

In addition it was found that a decrease in lance height and an increase in oxygen blowing rate both cause a temporary (additional) increase in the decarburization rate. It is known that both the lance height and oxygen blowing rate influence the amount of iron droplet formed due to jet impact. A decrease in lance height and an increase in oxygen blowing rate both increase the amount of iron droplets in the slag. Because part of the decarburization reaction takes place between these iron droplets and the slag, the increase in reaction surface between the iron droplets and the slag causes an increase in decarburization rate. The increased decarburization rate diminishes the iron oxide concentration in the slag, which in turn again decreases the decarburization rate.

It was also found that a step change in the iron ore addition rate does not have an immediate effect on the decarburization rate. The delay is most likely caused by the time needed to increase the temperature of the iron ore.

\section{ACKNOWLEDGMENTS}

The authors express their thanks to Danieli Corus for the financial support given to this work. Furthermore, we gratefully acknowledge Corus RD\&T and the OSF2 Corus IJmuiden for the provision of plant data. We also thank Corus RD\&T for the inspiring discussions.

\section{OPEN ACCESS}

This article is distributed under the terms of the Creative Commons Attribution Noncommercial License which permits any noncommercial use, distribution, and reproduction in any medium, provided the original author(s) and source are credited.

\section{TABLE OF SYMBOLS}

\begin{tabular}{|c|c|}
\hline$A$ & constant $(\mathrm{mol} / \mathrm{s})$ \\
\hline$A$ & frequency factor $(\mathrm{L} / \mathrm{s})$ \\
\hline$b$ & constant $(-)$ \\
\hline$c$ & constant $(\mathrm{mol} / \mathrm{ms})$ \\
\hline $\mathrm{C}$ & carbon content of steel (mol) \\
\hline$C_{\text {reaction }}$ & carbon used in reactions (mol) \\
\hline$[\mathrm{C}]$ & carbon concentration $\left(\mathrm{mol} / \mathrm{m}^{3}\right)$ \\
\hline$\left[\mathrm{C}^{*}\right]$ & carbon concentration $(\mathrm{mol} / \mathrm{mol})$ \\
\hline $\mathrm{CO}_{w g}$ & $\mathrm{CO}$ content wastegas $(\mathrm{mol} / \mathrm{mol})$ \\
\hline $\mathrm{CO}_{2, w g}$ & $\mathrm{CO}_{2}$ content wastegas $(\mathrm{mol} / \mathrm{mol})$ \\
\hline$E a$ & activation energy $(\mathrm{J} / \mathrm{mol})$ \\
\hline $\mathrm{FeO}$ & iron oxide in converter (mol) \\
\hline $\mathrm{FeO}_{\text {addition }}$ & iron oxide from additions (mol) \\
\hline $\mathrm{FeO}_{\text {lance }}$ & iron oxide from lance $(\mathrm{mol})$ \\
\hline$[\mathrm{FeO}]$ & iron oxide concentration $\left(\mathrm{mol} / \mathrm{m}^{3}\right)$ \\
\hline$\left[\mathrm{FeO}^{*}\right]$ & iron oxide concentration $(\mathrm{mol} / \mathrm{mol})$ \\
\hline$H_{\text {lance }}$ & lance height (m) \\
\hline$k_{0}$ & reaction rate constant $(\mathrm{mol} / \mathrm{s})$ \\
\hline $\mathrm{O}$ & oxygen content converter (mol) \\
\hline $\mathrm{O}_{\text {addition }}$ & oxygen from additions (mol) \\
\hline $\mathrm{O}_{\text {air }}$ & oxygen from air (mol) \\
\hline $\mathrm{O}_{\text {lance }}$ & oxygen from oxygen lance (mol) \\
\hline $\mathrm{O}_{w g}$ & oxygen in waste gas (mol) \\
\hline$p \mathrm{CO}_{2}$ & $\mathrm{CO}_{2}$ ratio in waste gasses $(\mathrm{mol} / \mathrm{mol})$ \\
\hline $\mathrm{R}$ & gas constant $(\mathrm{J} / \mathrm{Kmol})$ \\
\hline$T$ & steel temperature $(\mathrm{K})$ \\
\hline$V_{M}$ & molair volume $\left(\mathrm{m}^{3} / \mathrm{mol}\right)$ \\
\hline$V_{\text {steel }}$ & steel volume $\left(\mathrm{m}^{3}\right)$ \\
\hline$V \mathrm{O}_{2}$ & oxygen blowing rate $(\mathrm{mol} / \mathrm{s})$ \\
\hline$\phi_{w g}$ & flow rate waste gas $\left(\mathrm{m}^{3} / \mathrm{s}\right)$ \\
\hline
\end{tabular}

\section{REFERENCES}

1. G. Stephanopoulos: Chemical Process Control, an Introduction to Theory and Practice, Prentice Hall, Englewood Cliffs, NJ, 1984, pp. $45-46$.

2. B. Roffel and B. Betlem: Process Dynamics and Control: Modeling for Control and Prediction, John Wiley and Sons Ltd., Chichester, 2007, pp. 337-40.

3. B. Deo and R. Boom: Fundamentals of Steelmaking Metallurgy, Prentice Hall International, Hemel Hempstead, 1993, pp. 193-99.

4. F. Oeters: Metallugie der Stahlherstellung, Springer-Verlag, Berlin, 1989, pp. 381-82.

5. P.J. Kreijger: Stahl Eisenhütenwess., 1976, vol. 96, pp. 957-60.

6. D. Anderson and W.J. Henderson: Int. Oxygen Steelmaking Congr., Linz, 1987, pp. 595-607.

7. H. Zhi-Gang, L. Liu, H. Ping, and T. Ming-Xiang: Steeltimes Int., 2003, April-May, pp. 11-16. 
8. W. Dorr and W. Lanzer: Stahl Eisenhütenwess., 1973, vol. 93, pp. 187-84.

9. H.W. Meyer, W.F. Porter, G.C. Smith, and J. Szekely: JOM, 1968, July, pp. 35-42.

10. D.N. Ghosh: Ironmaking and Steelmaking, 1975, vol. 1, pp. 36-44.

11. T. Gare and G.S.F. Hazeldean: Ironmaking and Steelmaking, 1981, vol. 4, pp. 169-81.

12. E.W. Mulholland, G.S.F. Hazeldean, and M.W. Davies: J. Iron Steel Inst., 1973, Sept., pp. 632-38.

13. D.J. Min and R.J. Fruehan: Metall. Trans. B, 1992, vol. 23B, pp. 29-37.

14. Q.1. He and N. Standish: ISIJ Int., 1990, vol. 30, pp. 305-09.
15. W. Van Der Knoop, B. Deo, A.B. Snoeijer, G. Van Unen, and R. Boom: 4th Int. Conf. on Molten Slags and Fluxes, Sendai, 1992, p. 302-08.

16. A. Patuzzi and H. Alerl: Stahl Eisenhütenwess., 1990, vol. 110, pp. 81-84.

17. G. Brooks, Y. Pan, Subagyo, and K. Coley: Metall. Mater. Trans. $B, 2005$, vol. 36B, pp. 525-35.

18. Subayo, G.A. Brooks, and K.S. Coley: $C M Q$, 2005, vol. 44 (1), pp. 119-30.

19. Subayo, G.A. Brooks, and K.S. Coley: ISIJ Int., 2003, vol. 43 (7), pp. 983-89. 